\title{
Desde la doctrina racialista al separatismo en Cataluña: algunas reflexiones
}

\section{From the doctrine of race to separatism in Catalonia: some reflections}

\author{
Cristina Hermida del Llano \\ Universidad Rey Juan Carlos \\ ORCID ID 0000-0001-8213-3840 \\ cristina.hermida@urjc.es
}

Cita recomendada:

Hermida del Llano, C. (2020). Desde la doctrina racialista al separatismo en Cataluña: algunas reflexiones. Eunomía. Revista en Cultura de la Legalidad, 19, pp. 472-494.

doi: https://doi.org/10.20318/eunomia.2020.5724

Recibido / received: 23/08/2020

\begin{abstract}
Resumen
En este artículo, la autora debate sobre el derecho a decidir y más concretamente sobre si el referéndum en torno al futuro de Cataluña está prohibido en la Constitución española (CE). Se mantiene que sí que lo está en virtud del principio de indisolubilidad (art. 2.1. CE) y el de la soberanía nacional (art. 1.2. CE), sin olvidar los principios que caracterizan la democracia liberal española (arts. 1.1., 23.1, 9 y 10 CE). El artículo de Josep M. Vilajosana, titulado Democracia y derecho a decidir (2020) es tomado como base para el debate sobre esta cuestión. Se argumenta aquí cómo la interpretación evolutiva de los derechos democráticos vinculados a una concepción densa de la democracia no justifica la posibilidad de realizar un referéndum sobre la independencia de Cataluña, y todavía menos que puedan decidir unilateralmente los catalanes. Se destaca cómo la conciencia racial catalana ha servido de motor para el aumento del fervor secesionista, llegando a provocar, además de una contienda jurídica, una guerra de sentimientos y emociones.
\end{abstract}

\section{Palabras clave}

Legalidad, legitimidad, principios, democracia, derecho a decidir, Constitución española, Cataluña.

\section{Abstract}

In this paper, the author engages the debate concerning the right to decide, specifically concerning whether the referendum on the future of Catalonia can be prohibited within the Spanish Constitution. It is maintained that the answer is yes, given the principle of indissolubility (art. 2.1 of the Spanish Constitution) and of national sovereignty (art. 1.2. of the Spanish 
Constitution), while still affirming the principles that characterize Spain as a liberal democracy (arts. 1.1, 23.1, 9, and 10 of the Spanish Constitution). The article of Josep M. Vilajosana, entitled "Democracy and the right to decide" (2020) serves as the basis for the debate on this question. The argument here concerns how the evolutionary interpretation of democratic rights tied to a succinct conception of democracy does not justify the possibility of holding a referendum on the independence of Catalonia, and that, moreover, such a question cannot be decided unilaterally by the Catalan people. Here I highlight how the conscience of the Catalan race has served as motor to increase the secessionist fervor, which has unleashed, in addition to a legal dispute, a war of feelings and emotions.

\title{
Keywords
}

Legality, legitimacy, principles, democracy, right to decide, Spanish Constitution, Catalonia.

\begin{abstract}
SUMARIO. 1. Introducción: la gestación de un proceso inconstitucional 2. Algunas reflexiones en torno a la legitimidad y la legitimación, la moral crítica y la moral positiva. 3. El derecho a decidir de los ciudadanos sobre su futuro político. 4. ¿"Petrificación" de la Constitución española? 4.1. La Sentencia del Tribunal Constitucional 198/2012 de 6 de noviembre. 4.2. Antinomia valorativa. 4.3. Elecciones y consultas. 5. El derecho de autodeterminación de los pueblos: un mal argumento jurídico en la Sentencia del Tribunal Constitucional 114/2017, de 17 de octubre de 2017. 6. ¿Hacia dónde vamos? Un ulterior examen de la Sentencia del Tribunal Constitucional 114/2017. 7. El respeto de las minorías y la doctrina racialista en Cataluña. 8. El separatismo: una guerra de sentimientos y emociones
\end{abstract}

\section{Introducción: la gestación de un proceso inconstitucional}

Me gustaría comenzar agradeciendo al director de Eunomía. Revista en Cultura de la Legalidad, José María Sauca, su amable invitación a participar en el debate académico sobre el espinoso proceso político catalán que toma como base la sugerente y provocadora contribución en esta Revista de Josep M. Vilajosana, titulada Democracia y derecho a decidir (2020). En ella, con razón, se comienza reconociendo la transversalidad del tema que nos ocupa que, a mi modo de ver, por la complejidad que encierra, sobrepasaría las materias propias del Derecho Constitucional, la Teoría del Derecho y la Filosofía jurídico-política, abarcando otras disciplinas como la Historia del Derecho, el Derecho Internacional Público o, más concretamente, el Derecho de la Unión Europea, tal y como trataré de demostrar aquí.

La primera advertencia que querría realizar es que, a mi modo de ver, no se trata tanto de preguntarse sobre cómo debería responder sino cómo debería responder concretamente España, partiendo del marco jurídico-constitucional y de las normas internacionales a las que se vincula como Estado miembro de la Unión Europea

Un Estado democrático de Derecho en el siglo XXI ante una petición continuada y pacífica de una parte muy relevante de la población de una comunidad interna que reivindica el derecho a decidir sobre su futuro político, incluyendo la posibilidad de independizarse (Vilajosana, 2020). 
Precisamente el hecho de que España constituya un país plenamente soberano explicaría que los distintos poderes del Estado español puedan haber dado una respuesta completamente diferente a esta cuestión si se compara con la que hayan podido dar otros países democráticos en el mundo como Reino Unido o Canadá. Vaya por delante que la razón por la que creo que España no puede autorizar, delegar o simplemente tolerar un referéndum sobre la independencia de Cataluña es que la consulta se sitúa fuera del marco constitucional, esto es, la convocatoria de referéndum es inconstitucional tanto por razones sustantivas como competenciales, tal y como el propio Tribunal Constitucional proclamó en la STC $114 / 2017$, de 17 de octubre de 2017, en la que más adelante me detendré. A mi modo de ver, que ello fuera decidido de esta manera y no de otra, brinda seguridad jurídica al ciudadano español que felizmente constata cómo hay ciertos límites constitucionales que se salvaguardan por el alto tribunal y no se pueden traspasar.

El estallido del proceso político catalán, en el que aquí nos vamos a centrar, es resultado de convicciones arraigadas que han venido dando la cara a través de movimientos ciudadanos en los últimos años de nuestra historia más reciente. Recordemos que el 18 de febrero de 2006 se produjo una primera gran manifestación pública secesionista en las calles, con la afirmación «los catalanes somos una nación» y -se proclamaba- tenemos en consecuencia un «derecho a decidir». Ésta sería inmediatamente seguida por otra en diciembre de 2007 así como por una oleada de consultas cívicas a muchos ayuntamientos durante los años 2009, 2010 y 2011, basada en la iniciativa del ayuntamiento de un pueblo, Arenys de Munt, que había hecho una consulta a los vecinos sobre este asunto. Pronto se multiplicarían consultas municipales semejantes. A mi modo de ver, todas ellas tuvieron un éxito considerable como operaciones de movilización simbólica, cívica y transversal. La manifestación pública subsiguiente, de 2010, si recordamos, surgió por el hecho de que el pueblo había aprobado el proyecto de un nuevo Estatuto en 2006 y por la decisión del Tribunal Constitucional español que lo recortaba gravemente en su Sentencia $31 / 2010$, de 28 de junio de 2010.

Podría estar de acuerdo con Vilajosana en que el movimiento originado en Cataluña no supuso desde su inicio un ataque a la soberanía nacional; ahora bien, estudios sociológicos han avalado que durante el periodo de recesión económica más fuerte en España (2006-2014) el sentimiento independentista en Cataluña creció considerablemente a través de la creación de la Asamblea Nacional Catalana (ANC) en marzo de 2012, y de algunas asociaciones como Omnium Cultural, comprometidas con el fomento «cívico del soberanismo».

Tras la aprobación de la Ley del Referéndum sobre la Independencia de Cataluña por parte del Gobierno catalán la situación se fue tornando cada vez más compleja hasta límites insospechados, entre otras razones, porque se pretendía justificar lo injustificable. Tratemos de recordar aquí cómo se sucedieron los hechos porque éstos hablan verdaderamente por sí solos: primero, tras una intensa, tensa y además larga sesión en el Parlament por las fuertes diferencias entre la mayoría separatista de JxSí y la CUP y los grupos de la oposición, se aprobó el 6 de septiembre de 2017 la Ley del Referéndum, contando con los 72 votos de la mayoría independentista y las 11 abstenciones de Catalunya SíQueEsPot en un hemiciclo que se encontraba medio vacío. Ello quiere decir que el 6 de septiembre de 2017 el Govern en pleno había firmado el decreto de convocatoria del referéndum de autodeterminación de Cataluña, programado para el día 1 de octubre de 2017.

Finalizada la votación, la presidenta de Ciutadans, Inés Arrimadas, anunció por sorpresa la presentación de una moción de censura contra Puigdemont, con el único compromiso de «convocar elecciones». Aunque Ciudadanos no contaba con 
apoyos suficientes para sacar adelante una eventual moción de censura, con la presentación de la misma se pretendía paralizar todo el proceso parlamentario de tramitación del resto de leyes de desconexión, como era el caso de la Ley de Transitoriedad Jurídica. Por otra parte, en el ámbito legal la Fiscalía Superior de Catalunya anunciaba una querella ante el Tribunal Superior de Justicia de Cataluña contra los miembros de la Mesa que aprobaron la admisión a trámite de la Ley del Referéndum.

A partir de entonces, los hechos se suceden a gran velocidad. El pleno del Parlament elige el 7 de septiembre de 2017, a los cinco candidatos presentados por Junts pel Sí (JxSí) y la CUP como vocales de la Sindicatura Electoral, órgano con funciones similares a una Junta Electoral, en una votación en la que no participaron los diputados de Ciudadanos, PSC y PPC, de tal modo que los cinco vocales de la Sindicatura Electoral fueron elegidos únicamente con los votos de JxSí y la CUP y la abstención de Catalunya Sí Que Es Pot. Por otra parte, se lleva adelante la aprobación de la Ley 20/2017 de 8 de septiembre, de Transitoriedad Jurídica y Fundacional de la República, la principal ley de desconexión con el Estado, impulsada por JxSí y la CUP, y con los votos a favor de los cuatro miembros de JxSí en la Mesa, incluida la presidenta del Parlament, Carme Forcadell, el voto contrario de los representantes de Ciudadanos y el PSC, y la abstención del representante de Catalunya Sí Que Es Pot. La ley de Transitoriedad establecería un periodo provisional para regular el tránsito entre la Cataluña autonómica y la independencia, para impedir que se produjera llegado el caso un vacío legal.

Ahora bien, estas actuaciones por parte del bloque independentista tendrían una rápida y contundente respuesta por parte de organismos catalanes que pusieron en duda la legalidad de la tramitación de las leyes de desconexión: por una parte, el Consell de Garanties Estatutàries, encargado de analizar la adecuación de las normas a la Constitución y el Estatut, dio la razón a los grupos del PSC y de Ciutadans al avalar en una resolución un dictamen sobre la tramitación exprés de la Ley del Referéndum; y, por otra parte, los letrados del Parlament advirtieron a la Mesa que tramitar la Ley del Referéndum y la de Transitoriedad Jurídica suponía desobedecer al Tribunal Constitucional.

Es entonces cuando además, el que fuera entonces presidente del Gobierno, Mariano Rajoy, convocó un Consejo de Ministros extraordinario en aras de presentar un recurso ante el Tribunal Constitucional para solicitar la nulidad de la Ley del Referéndum, aduciendo la necesidad de defender el principio de legalidad, la soberanía nacional, la dignidad de las instituciones y la propia legalidad autonómica de Cataluña. El fiscal general del Estado anunciaría también querellas contra miembros de la Mesa del Parlament catalán y contra todos los miembros del Govern de la Generalitat.

En paralelo, el presidente de la Federación Española de Municipios y Provincias, Abel Caballero, advertía a los ayuntamientos que no podían colocar urnas «bajo un mandato ilegítimo» y, en consecuencia, debían rehusar la carta remitida por Puigdemont y Junqueras a los alcaldes catalanes para que pusieran a disposición del Govern los locales en los que habitualmente se hubiesen venido celebrando elecciones.

En esta primera etapa, a mi juicio, emerge una tesis crucial para abarcar el problema desde la raíz y en su totalidad, defendida por Caballero a principios de septiembre de 2017: "se trata de un proceso anticonstitucional, y los ayuntamientos tienen que estar con la legalidad y defendiendo la ciudad». Tengamos en cuenta que a quien en última instancia va dirigido el Estado de Derecho es al propio Estado, es 
decir, a sus órganos y poderes, a sus representantes y gobernantes, en el sentido de que todos ellos deben actuar con sometimiento a las normas jurídicas, conforme dictamina el imperio de la ley, el principio de legalidad, «en el más estricto sometimiento a dicho marco institucional y constitucional» (Díaz, 1966; Díaz, 1998).

EI PSOE planteó desde muy pronto la creación de una comisión parlamentaria para la «evaluación y modernización del Estado autonómico» con el fin de mostrar su apoyo al proyecto del Partido Popular y a Ciudadanos, dejando así aparcada su iniciativa de reforma federal de la Constitución española. Según señalaban los diputados y diputadas del Grupo Parlamentario Socialista en su escrito de 7 de septiembre de 2017 dirigido a la Mesa del Congreso, la Comisión

tendría por objeto analizar las necesidades actuales del modelo de organización territorial en España y realizar las propuestas que considere necesarias de mejora institucional, normativa y de todo tipo, en relación con el modelo y la política territorial, y específicamente para desbloquear el actual desencuentro en relación con la cuestión catalana y aportar soluciones satisfactorias que susciten el apoyo mayoritario en Catalunya y en el resto de España (Grupo Parlamentario Socialista, 2017, p. 3)

En realidad, no quedaba más remedio que luchar con las armas del Estado de Derecho para combatir esa escalada de autoritarismo, que había sido impulsado mediante la estrategia de poner las instituciones al servicio del independentismo. Buena prueba de que los independentistas catalanes habían cruzado la línea roja era, dicho de forma resumida, que en su desafío al Estado, el Parlament había aprobado la cuestionable Ley del Referéndum, sin los votos de Ciutadans, del PSC y del PPC, cuyos diputados se habían visto forzados a abandonar el hemiciclo por ir en contra de lo que proclamaba el Estatut y el Consell de Garanties Estatutàries. El recurso ante el Tribunal Constitucional tendría por objeto velar por defender la legalidad en Cataluña.

Aquí se vislumbra una segunda tesis fundamental para nuestro tema: no se puede defender la postura del independentismo o la ruptura de la soberanía nacional por encima de las normas democráticas constitucionales, que nos hemos dado todos los españoles.

2. Algunas reflexiones en torno a la legitimidad y la legitimación, la moral crítica y la moral positiva

Aunque las reivindicaciones provenientes de los partidarios del llamado «derecho a decidir», pudieran ser legítimas en una vertiente, en realidad, en ningún caso estaban amparadas por la legalidad, lo que me hace distanciarme de la opinión mantenida por Vilajosana (2020). Por el contrario, sí que estaría de acuerdo en que sobre la legitimidad pueden darse versiones muy distintas (Díaz, 1978; Díaz, 1984; Díaz, 1996) aunque, a decir verdad, siguiendo a Elías Díaz, creo que resulta mejor diferenciar dentro de ella estas dos dimensiones: por una parte, la legitimidad social o legitimación que adquiere una norma, una institución, una decisión, una persona o grupo de personas mediante el respaldo fáctico o la adhesión racional de hecho del grupo social. Según esta primera versión de la legitimidad, cuanto mayor sea en términos cuantitativos, es decir, sociológicos, la adhesión social del grupo que respalda la norma, la decisión, el ordenamiento jurídico, etc... podremos decir que cuenta con mayor dosis de legitimación o legitimidad social, siendo esto a lo que Vilajosana denomina legitimidad formal. Pero, junto a ella, por otra parte, estaría la legitimidad material (o en sentido substantivo) que efectivamente, $-\mathrm{y}$ ahí coincido con el autor- nos conduce a afirmar que una norma es legítima si no vulnera lo que dispone la moral. 
Es obvio que, siguiendo la estela de Hart, deberíamos defender con ahínco la existencia de una moral crítica -y en ello comparto también la opinión de Vilajosanafrente a la moral social o positiva puesto que ésta solamente responde a la idea de una moral fáctica o de hecho (Laporta, 1993; Laporta, 1995). No olvidemos que frente al emotivismo de Devlin, que defendía que los enunciados éticos no son cognoscibles, Hart propuso, con acierto, que las verdades morales han de ser accesibles a través de la razón y que la moralidad positiva debe ser susceptible de cualquier tipo de crítica (Hart, 2007; Maccormick, 2010).

\section{Patrick Devlin defendió en una conferencia impartida en 1958 que}

las convicciones morales profundas compartidas por los miembros de una comunidad no son rasgos accidentales e históricos de esa comunidad, sino que forman parte, o son elementos estructurales, de su propia identidad como sociedad. De forma tal que si se alteran o traicionan esas convicciones morales la sociedad cambia de identidad, se desintegra como tal. Es decir, que una amenaza a los rasgos básicos de la moralidad positiva hace peligrar a la sociedad misma (Laporta, 1995, p. 49).

Justamente, estas tesis fueron las que le condujeron a Devlin a sostener que las leyes tienen la misión de defender coactivamente la pervivencia de esa moralidad, porque con ello conseguimos, a fin de cuentas, que se mantenga incólume la sociedad. A mi modo de ver, si estas ideas que amparan lo que se conoce como «moralismo legal», son completamente erróneas es porque, como ya sostuviera Hart, parece mucho más razonable pensar que las sociedades evolucionan al ritmo de cambios en la moral social colectiva, sin que por ello las sociedades perezcan o nazcan en un momento determinado.

En esta misma línea, el propio Dworkin ha afirmado, conforme explica Laporta, que

los prejuicios, las reacciones puramente emocionales (por ej. reacciones de asco), los errores de hecho o los argumentos de autoridad no eran ingredientes de una posición moral, sino elementos de una mentalidad tópica que no podían valer como criterios de moralidad. La moralidad, la 'posición moral', demandaba unos controles de racionalidad, universalizabilidad, etc. [...] Precisamente, Dworkin, al exigir a las posiciones morales una serie de controles de racionalidad, estaba implicando que hay límites morales que las leyes no deben traspasar aunque sean el producto de una decisión mayoritaria (Laporta, 1995, p. 51).

Desde este punto de vista, es obvio que existen razones morales para criticar, por ejemplo, la brutal y terrible práctica de la Mutilación Genital Femenina por violar derechos de la salud física y psíquica de la mujer, llegando a haber sido definida la ablación del clítoris como la "extirpación de la felicidad», tal y como dejé puesto de manifiesto en mi monografía titulada La Mutilación Genital Femenina. El declive de los mitos de legitimación (Hermida, 2017). Siguiendo estas ideas, sería necesario recurrir a criterios morales independientes sobre la corrección de contenido y límites del derecho positivo en aquellos países en los que la moral social es proclive a la Mutilación Genital Femenina. Si se me permite el inciso, por desgracia, son muy pocas las veces que la mujer tiene la potestad de decidir, incluso cuando se trata de cuestiones que le afectan directamente, en buena parte debido a que las sociedades están estructuradas en virtud de relaciones de poder, esto es, de relaciones de dominación y de subordinación (Weber, 1993, pp. 43-45), en las que la mujer generalmente se encuentra sometida, subordinada al varón, careciendo del principio de responsabilidad personal en el sentido dworkiano. 
En definitiva, recapitulando, y conectándolo con la cuestión que aquí nos ocupa, los independentistas alegarían la legitimidad sociológica o legitimación fáctica para defender su derecho a decidir sobre el futuro político de Cataluña, olvidando que el Derecho no existe para reforzar la moral social del grupo. Quedémonos pues con la famosa distinción de Hart entre la moralidad positiva que es aquella «efectivamente aceptada y compartida por un grupo social dado» y la moralidad crítica que son «los principios morales generales usados en la crítica de las instituciones sociales reales incluida la moralidad positiva» (Laporta, 1995, p. 52). En todo caso, como ya se ocuparon de resaltar grandes filósofos como Thomasius o Kant, a través de la distinción entre forum interno y externo, la moral crítica es autónoma, es decir, no heterónoma, lo que nos permite vincularla con la idea de la moral inherente a los derechos humanos.

Me gustaría matizar aquí que no se pueden confundir los derechos humanos con los derechos fundamentales porque la moral crítica pertenece al ámbito de los derechos humanos pero no necesariamente al de los derechos fundamentales ya que éstos finalmente son derechos humanos positivizados (Ferrajoli, 2001). Es más, la transformación de los derechos humanos en derechos fundamentales es lo que convierte a estos últimos dentro de la tradición democrático-liberal en el corazón intangible de las Constituciones, siendo el ingrediente principal que confiere identidad a los Estados (Tinnefeld y Schmale, 2010). En virtud de esta diferenciación, debería quedar claro que una cosa son los derechos morales y otra los derechos jurídicopositivos (Robles, 1988; Robles, 1992; Hermida, 2005). Por ello la Constitución española como norma fundamental del Estado no debería tampoco estar exenta de una mirada desde la moral crítica y, de hecho, por ello están establecidas normas constitucionales que estipulan los criterios que hacen posible la reforma de la Constitución llegado el caso.

\section{El derecho a decidir de los ciudadanos sobre su futuro político}

La primera cuestión que habría que aclarar es que el derecho a decidir no debería ser confundido con el derecho a la autodeterminación, como ha resaltado Vilajosana (2020). Ahora bien, a la pregunta sobre si la Constitución española permite que la Generalitat plantee una consulta a los catalanes sobre su futuro político «independentista», creo que habría que responder con un «no» rotundo. Precisamente, siguiendo a Von Wright (1971), cabría demostrar que la Constitución española no permite realizar una consulta a la ciudadanía de Cataluña sobre su futuro político independentista. De alguna manera podríamos decir que existen algo así como reglas definitorias o determinativas, en la terminología de Von Wright, que nos permiten movernos dentro del juego democrático constitucional y si cambiamos una de esas reglas que gozan de cierta rigidez, de raíz y unilateralmente, "el juego» constitucional aprobado en 1978 por todos los españoles cambia completamente o, por decirlo así, se transforma en otro distinto.

Desde mi punto de vista, una de esas reglas que nos hemos dado todos los españoles a través de la Constitución española (CE) y que regulan el caso planteado por la pregunta anterior sería el art. $2 \mathrm{CE}$, que recoge la indisoluble unidad de la nación española, o el art. 1.2 CE referido a la soberanía del pueblo español. Estas disposiciones no pueden entrar en discusión con el principio democrático establecido como pórtico en el art. 1.1. CE, que se concreta en otras disposiciones de la Constitución española, como el de participación política del art. 23.1 CE. En definitiva, no cabe plantear una polémica entre estas disposiciones constitucionales, entre otras razones, porque la ponderación no puede implicar que uno de los principios en juego quede para siempre exterminado. Esto es lo que se pretende desde el separatismo independentista, que el art. 2 CE diga algo diferente de lo que en realidad dice o deje 
de proclamar lo que claramente estipula saltándose el tenor literal de la norma constitucional. Con otras palabras: en virtud de la primacía absoluta del principio de indisolubilidad del art. $2 \mathrm{CE}$, efectivamente, no sería posible una consulta sobre la independencia de una parte del territorio estatal y, en consecuencia, no habría ninguna circunstancia concebible en que el principio democrático pudiera prevalecer frente a este precepto.

Es cierto que tanto la doctrina como la jurisprudencia del Tribunal Constitucional han venido admitiendo que no hay derechos ilimitados y que la herramienta de la ponderación entre principios serviría precisamente para no entender ninguno de ellos de forma absoluta (Alexy, 1993) pero ello es lo que precisamente hace que gane en la imaginaria contienda el art. $2 \mathrm{CE}$. Del mismo modo que no es posible realizar esta consulta bajo manto legal, tampoco reconoce la Constitución española un derecho a la autodeterminación. Según esto, parece, a todas luces, razonable la afirmación de Vilajosana (2020) de que «la declaración unilateral de independencia por parte de la Generalitat, como el ejemplo típico de ejercicio de aquel derecho, no tendría cobertura constitucional, aunque la hagan los representantes democráticamente escogidos».

\section{4. ¿«Petrificación» de la Constitución española?}

Alegar el argumento de «la petrificación» de la Constitución española desde la postura independentista, a mi modo de ver, resulta tendencioso ya que induce maliciosamente a pensar que se pretende salvaguardar o santificar el inmovilismo jurídicoconstitucional cuando en realidad de lo que se trata es de invocar un argumento de "respeto» al texto constitucional que nos hemos dado todos los españoles, tras un debate pacíficamente consensuado. Es por ello que, como ya señalé anteriormente, tratar de enfrentar el principio de indisolubilidad y el principio democrático (que, en realidad, encubiertamente encierra el derecho de autodeterminación) me parece un error y una estrategia astuta pero equivocada para los partidarios de la consulta sobre el futuro político independentista en Cataluña. Estaría de acuerdo en que la forma en que el constituyente entendió la democracia es la que hay y no puede ser alterada salvo, por supuesto, una modificación expresa del texto constitucional, como ya dije, siempre conforme a las normas constitucionales estipuladas a tal efecto en el art. 168 CE.

\subsection{La Sentencia del Tribunal Constitucional 198/2012 de 6 de noviembre}

Es cierto, y sobre ello creo que no se albergan dudas, que el uso de la interpretación evolutiva goza de una larga tradición en la jurisdicción internacional y, más en concreto, en la del Tribunal Europeo de Derechos Humanos a la hora de interpretar el Convenio Europeo para la protección de los Derechos Humanos y de las Libertades Fundamentales firmado en Roma en 1950 (Prebensen, 2000, pp. 1123-1138). De hecho, también se ha utilizado este criterio interpretativo, entre otros, por el Tribunal Internacional de Justicia, por el Tribunal de Justicia de la Unión Europea, por la Corte inter-americana de Derechos Humanos o por el Comité de Derechos Humanos de las Naciones Unidas.

Estoy de acuerdo con Vilajosana en que buena muestra de la importancia de la interpretación evolutiva en nuestro entorno español, ha sido la decisión del Tribunal Constitucional en la Sentencia 198/2012 de 6 de noviembre (BOE, 28 de noviembre de 2012) ya que el alto tribunal se sirvió de ella para demostrar el alejamiento de la voluntad de los constituyentes respecto de la institución matrimonial, admitiendo que la modificación del Código Civil, que permite el matrimonio entre personas del mismo sexo, sea constitucional. Me hubiera parecido mucho más correcto, desde el punto 
de vista jurídico, llegar a este mismo resultado del fallo pero argumentando de otra manera, es decir, haciendo uso de otros parámetros interpretativos. Como bien indica Vilajosana y en ello estaría también de acuerdo con él, el Tribunal Constitucional cometió el error en la sentencia STC 148/2012 de identificar la interpretación evolutiva con una mera constatación fáctica empírica de un supuesto cambio en los valores dominantes de la sociedad, ignorando la importancia de la moral crítica en su argumentación. Por otra parte, conforme destaca Ollero en el fallo, aunque es cierto que el criterio de la interpretación literal de las normas puede ser a veces insuficiente a la hora de precisar su sentido, ello no quita para que sea «siempre obligadamente el primero de ellos; sobre todo en una norma como la constitucional cuya relevancia se apoya en su postulada rigidez» (Ibid., p. 212).

Como ya he destacado en otros escritos (Hermida, 2015), la interpretación evolutiva ha venido ganando fuerza en los últimos años en España no sólo a la hora de redimensionar viejos derechos sino generando el nacimiento de derechos nuevos, es decir, convirtiéndose en la mejor aliada para gestar derechos hasta la fecha inexistentes. Buena prueba deja de ello es la jurisprudencia de nuestro Tribunal Constitucional, que ha transformado "viejos derechos» en otros verdaderamente nuevos y bien distintos sirviéndose de esta herramienta interpretativa. Lo que sucede es que un mal uso de este criterio interpretativo, con claro fundamento en nuestro ordenamiento jurídico positivo (art. 3.1 Código Civil), en realidad, ha puesto los derechos fundamentales al servicio de la opinión de la mayoría social, desnaturalizando de algún modo la función para la que aquéllos fueron creados. Ello lo observamos con nitidez, como ya se ha resaltado, en la problemática sentencia del TC 198/2012, de 6 de noviembre de 2012.

Me parece un error convertir al juez constitucional en sociólogo, reafirmando con ello la postura característica del realismo jurídico como concepción del Derecho que destaca por encima de todo la legitimidad socialmente eficaz. Veamos un par de párrafos de la sentencia:

La institución matrimonial se mantiene en términos perfectamente reconocibles para la imagen que, tras una evidente evolución, tenemos en la sociedad española actual del matrimonio, como comunidad de afecto que genera un vínculo o sociedad de ayuda mutua entre dos personas que poseen idéntica posición en el seno de esta institución (Ibid., p. 202)

o, como se precisa en otro lugar, la Constitución «a través de una interpretación evolutiva se acomoda a las realidades de la vida moderna como medio para asegurar su propia relevancia y legitimidad», lo que da a entender que es la Constitución la que debe adaptarse a los vaivenes de la sociedad y no al revés (Ibid., p. 213), dejando los derechos fundamentales en manos de la opinión coyuntural de la mayoría social.

De hecho, como se desprende de estos extractos de la sentencia del alto tribunal, lo que determina el contenido del derecho al matrimonio es, a fin de cuentas, la opinión que respecto al mismo albergue la mayoría de la sociedad, lo que, si lo pensamos dos veces, realmente induce al desconcierto, a la confusión y sobre todo a la inseguridad jurídica de los ciudadanos. Como ya dije en otro lugar,

los derechos fundamentales, a la luz de este fallo, parecen haber dejado de ser criterios de legitimidad y justicia, o la plataforma de la moral crítica, en palabras de Hart, para pasar a convertirse en herramientas que modela a su antojo la moral mayoritaria, interpretada ésta por una serie de magistrados del Tribunal Constitucional. Dicho de otro modo: no se trata tanto de interpretar la Constitución sino de cómo colmar su contenido a partir de las opiniones de la moral mayoritaria. ¿Se 
pueden cambiar instituciones por el mero hecho de que la moral dominante considere que ello es lo correcto? La respuesta es obvio que sí, como aquí se hizo, pero queda aún por contestar si ello es legítimo o no (Hermida, 2015).

Mejor no pudo responder a esta cuestión, a mi modo de ver, el magistrado Aragón Reyes en el fallo cuando resalta que

el núcleo, la imagen maestra, de una garantía institucional no puede someterse a los avatares de la cultura jurídica a lo largo del tiempo. Precisamente para evitar que el legislador ordinario, atendiendo al supuesto clamor de la calle, las estadísticas y los estudios de opinión, pueda vulnerar la Constitución, se crearon los Tribunales Constitucionales. De otro lado resulta muy peligroso sentar el principio de que las normas pueden no decir lo que dicen, sino lo que se quiere que digan (Ibid., p. 204).

Esta aseveración de Aragón es relevante para nosotros porque advierte del peligro de que la legitimación formal o sociológica termine creando criterios de legitimidad material, lo que resulta, a mi modo de ver, a todas luces alarmante, si pensamos en los riesgos a los que puede conducir la tiranía de la mayoría social en términos morales.

Es más, en la sentencia citada daba la decepcionante impresión de que el Tribunal Constitucional se convertía en un órgano cuya como misión no era tanto velar por el respeto a la Constitución sino por el respeto de lo que la mayoría pudiera opinar coyunturalmente en términos morales. Como precisó el magistrado Rodríguez Arribas, al hacer esto no sólo se estaba desnaturalizando el matrimonio sino el órgano mismo del Tribunal Constitucional, al perder la función inherente al mismo (Ibid., p. 204). En esta misma línea, el magistrado Ollero advertiría también que aceptar esta interpretación «equivaldría a admitir que no es la Constitución la que certifica y garantiza la legitimidad de las conductas sociales y políticas, sino que sería su texto el que cobraría legitimidad acomodándose a ellas» (Ibid., p. 213). Me parece más que razonable la postura que adopta este magistrado, filósofo del Derecho, alejándose de la corriente actual que concibe evolutivamente el concepto constitucional de garantía institucional, haciendo depender, en consecuencia, su contenido de la mudable y cambiante percepción social.

Si estas reflexiones son enjundiosas es porque además desde la perspectiva de Ollero claramente se rechaza la postura tanto de los que afirman que el contenido esencial de los derechos fundamentales emana de la misma naturaleza jurídica del precepto como la de aquellos que preguntan a la opinión pública para determinar su alcance, desligándolo de toda fundamentación metafísica-ética, actuando de alguna manera conforme a un modo paternalista.

Ollero no duda en reconocer abiertamente que el verdadero fundamento de los derechos en aras de que estén eficazmente protegidos nos traslada a una antropología necesaria que hay que desvelar puesto que en muchas ocasiones ésta queda ensombrecida por aquellos que intentan negar los derechos humanos y/o dejan los derechos a expensas de los vaivenes propios de la razón de Estado. Es por ello que para Ollero

el ajustamiento o delimitación jurídica, que debe realizar el juez en cada caso concreto, se produce a través de una cadena de juicios de valor que deberá tener en cuenta, en todo momento, las condiciones convivenciales en las que se desarrolla cada derecho, buscando luego fundamento en el marco consensual del ordenamiento para no romper la relación de simetría (Aparicio, 2013). 
Creo que lo que, finalmente, Ollero trata de transmitir a través de su voto discrepante en esta sentencia es la confusión reinante entre lo que es Derecho y lo que es moral, a mi modo de ver, por cierto, una de las aportaciones o tesis principales de su pensamiento (Ollero y García Amado y Hermida del Llano, 2012). Recordemos que el Derecho debería ser entendido como «un mínimo ético indispensable para garantizar suficientemente una convivencia que merezca considerarse humana» (Ollero, 2013a), a sabiendas de que estas exigencias jurídicas por ser mínimas no por ello son menos importantes al constituir la «condición previa para el logro de cualquier maximalista aspiración moral» (Ollero, 2013a). Dicho de otro modo: el Derecho es ese mínimo ético tan indispensable que al final termina generando una obligación moral (Ollero, 2013b, p. 3).

De estas reflexiones iusfilosóficas de Ollero se deriva una tesis que me parece fundamental para el tema que nos ocupa, y es que no cabe identificar el Derecho con la voluntad del que manda porque a no ser que seamos defensores del positivismo jurídico ideológico (Bobbio, 1965, pp. 105-106), nadie suscribiría que el Derecho, entendido como órdenes respaldadas por el uso de la fuerza, puede generar obligaciones morales. Frente al Derecho concebido como instrumento coactivo al servicio de los poderes del Estado, parece más razonable pensar que lo que aquel propone es un conjunto de exigencias de cuyo respeto derivaría su propia legitimidad. De esta manera no es un criterio cuantitativo mayoritario el que determina el mínimo ético a garantizar en sociedad, sino «cualitativas exigencias jurídicas objetivas las que deben imponerse, incluso contra la mayoría» (Ollero, 2014).

\subsection{Antinomia valorativa}

Al partir de la premisa principal que sostiene que el Derecho presenta una textura abierta donde hay lagunas y antinomias, alguien podría entender que el caso que debatimos constituye una incompatibilidad normativa no desde el punto de vista lógico ni empírico, sino desde una perspectiva axiológica (Ezquiaga, 2010, p. 21). Es por ello obligado recordar aquí que en caso de estar ante una antinomia valorativa de principios, la forma de solucionar dicha antinomia exigiría la ponderación de los principios o valores en conflicto en el caso concreto para que ninguno de los dos principios quedase anulado, cosa que como vemos ocurriría de optar por que Cataluña se separara del resto de España, al quedar anulado ipso facto el art. 2 CE. Insisto, con otras palabras: por ser el concepto de indisolubilidad de la nación un concepto constitucionalmente rígido y blindado, la interpretación evolutiva no puede amparar el separatismo de Cataluña o el derecho a decidir unilateralmente de los catalanes porque ello generaría una antinomia valorativa de principios inaceptable dentro de nuestro ordenamiento jurídico. Es por ello que no deberíamos dejarnos llevar por el espejismo que crea la Sentencia 198/2012, al haber puesto conceptos más o menos abiertos o redefinibles, incluso valores como el de la igualdad, al servicio de objetivos que terminan relativizando a los primeros cuando en realidad deberían servir de fundamento a la posible redefinición de derechos, al ser "exigencias éticas tan objetivas como racionalmente cognoscibles" (Ollero, 2013a).

\subsection{Elecciones y consultas}

Estaría completamente de acuerdo con la apreciación de Vilajosana (2020) de que las elecciones y las consultas pueden convivir perfectamente en armonía constitucional por no tratarse de procedimientos excluyentes. Es más, efectivamente, ambos convierten nuestra democracia en una de más calidad, más «densa», lo que precisamente justifica la existencia del derecho fundamental del que gozan los ciudadanos a poder participar directamente en los asuntos públicos, tal y como se reconoce en el artículo 23.1 CE. Ahora bien, lo que debería quedar claro es que el 
legislador autonómico no puede convocar un referéndum sobre la independencia de Cataluña de forma unilateral, poniendo en entredicho los arts. 1.2 y $2 \mathrm{CE}$, en relación con el art. $168 \mathrm{CE}$.

$\mathrm{Si}$ atendemos a posibles experimentos mentales, me parecería razonable pensar que el sujeto relevante de este tipo de consultas debería ser no solo el pueblo catalán sino la totalidad del pueblo español hasta el punto de que esa opinión mayoritaria valdría tanto para vetar la independencia como para validar la expulsión aun en contra de la posible opinión negativa de los propios catalanes. Estoy así de acuerdo con los que postulan que la democracia implica el principio de la mayoría pero, desde luego, sin impedir nunca que una determinada minoría pueda llegar a convertirse un día en mayoría desde el respeto escrupuloso al principio de legalidad. Esto es algo que no debería olvidarse.

Por otra parte, no me parece adecuado apelar al imperativo kantiano de que los seres humanos son fines en sí mismos para argumentar en favor del derecho a decidir sobre el futuro político de Cataluña. Tratar a las personas con la dignidad que merecen no supone tomarse siempre en serio todas sus creencias, sus opiniones, sus decisiones sean cuales sean éstas, sobre todo, cuando éstas contravienen normas elementales de convivencia dentro de un Estado democrático y perturban el orden social o el orden moral desde la perspectiva de la moral crítica. Esto sirve para lo que antes dijimos sobre la Mutilación Genital Femenina.

Sobran ejemplos que demuestran que es un riesgo inasumible amparar decisiones entre personas con igual dignidad, sin dar ningún valor a las razones por las que acaban decidiendo. Lo importante es lo que se vota para hablar de legitimidad porque el voto desnudo no legitima independientemente de las razones que cada uno tenga para emitirlo. En consecuencia, se trataría de averiguar si porque se impida la consulta independentista los catalanes pierden su capacidad de reflejar su juicio más profundo sobre cómo desempeñar su responsabilidad soberana por su propia vida y, por tanto, no disfrutan del denominado por Dworkin como «principio de la responsabilidad personal» (Dworkin, 2006; Dworkin, 2008, pp. 25, 33-37, 101 y 103).

Como ya hemos dicho, a diferencia de la moral, el Derecho no busca hacer al ciudadano, feliz, rico o santo, al limitarse a «mantener un marco normativo mínimo que le posibilite aspirar a esos o cualesquiera otros legítimos objetivos personales» (Ollero, 2013a), porque lo contrario sería caer en el paternalismo o en el totalitarismo, como ya puso de relieve Kant. Como Vidal con acierto ha resaltado:

el mayor riesgo que amenaza la autonomía moral y la libertad del sujeto para Kant no es tanto el Estado absoluto o totalitario cuanto el Estado paternalista, que anula la capacidad moral y la autonomía del sujeto y pone en peligro la dignidad del ser humano que más allá de las consabidas declaraciones retóricas al uso consiste específicamente ser el modelador y definidor de sí mismo, en que tenga la condición de ser aquello que quiera ser, en una línea de pensamiento que se reafirma en el Renacimiento y sobre todo en la llustración y en Kant y que todavía seguimos utilizando para adscribir la condición de ser persona: vivir nuestra vida de acuerdo con un plan, proponernos una identidad propia a través de nuestros propósitos, de lo que intentamos ser y hacer en la vida (Vidal, 1999, p. 166). 
5. El derecho de autodeterminación de los pueblos: un mal argumento jurídico en la Sentencia del Tribunal Constitucional 114/2017, de 17 de octubre de 2017

Sobre esta cuestión resulta obligado volver la mirada a la sentencia del Tribunal Constitucional 114/2017, de 17 de octubre de 2017, porque allí se deja patente la inexistencia de un supuesto derecho de secesión del pueblo catalán sobre la base del derecho de autodeterminación de los pueblos. No deja de resultar cuanto menos curioso que, como resalta la sentencia, el preámbulo de la Ley impugnada calificara el derecho de autodeterminación como "el primero de los derechos humanos», tratando de construir sobre el derecho Internacional y los Pactos sobre derechos Civiles y Políticos de Naciones Unidas una supuesta legitimidad democrática que fundamentara la decisión de aprobar esa Ley, que paradójicamente se vinculaba a las previsiones constitucionales sobre convenios internacionales.

El TC no dudó en reconocer, con sumo acierto, que ni del Derecho Constitucional ni del Derecho Internacional podía derivarse la existencia de este derecho. Observando el Derecho Comparado, se comprueba que apenas ninguna Constitución reconoce en la actualidad un derecho de secesión de una parte del territorio de un Estado. Es más, ni tan siquiera los Tribunales Supremos de los Estados federales con un mayor grado de descentralización territorial han aceptado una posible aspiración secesionista (caso Texas vs. White, de 1868, del Tribunal Supremo de los Estados Unidos, y la declaración del Tribunal Supremo de Canadá, de 20 de agosto de 1998, que mantuvo que la secesión de Quebec solo sería factible si previamente se realizaba una reforma de la Constitución federal).

Aunque el preámbulo de la Ley cita los arts. 10.2 y 96 CE como base jurídica para fundamentar su contenido, a decir verdad, el Derecho Internacional no recoge un derecho a la autodeterminación en el seno de un Estado con un sistema constitucional íntegramente democrático como el español. En definitiva, en el ámbito del Derecho Internacional no se encuentra base alguna desde la que poder sostener la posibilidad de un derecho de secesión.

En el caso español, quedó más que confirmada la inexistencia de un derecho de secesión (arts. 1 y 2 CE) y, como criterio de interpretación teleológico, recordó la sentencia que durante los debates constituyentes se había bloqueado frontalmente una propuesta en favor de que se reconociera expresamente el derecho de autodeterminación de los pueblos del Estado. Por último, tampoco cabría hablar, en consecuencia, de un «derecho a decidir» en el sentido empleado por la Declaración de soberanía y del derecho a decidir del pueblo de Cataluña, de 23 de enero de 2013, conforme había ya establecido el Tribunal Constitucional con anterioridad (STC 42/2014).

Es más, del propio principio básico del Estado de derecho (rule of law) se sostiene que cualquier intento de creación de un Estado en violación del propio Derecho interno estatal constituye en sí mismo una conculcación del Derecho Internacional puesto que éste vela por que los ordenamientos jurídicos nacionales se respeten por sus ciudadanos. En este contexto, el Derecho Internacional contemporáneo salvaguarda el principio de integridad territorial y así de hecho lo ha reconocido la propia Declaración de la Asamblea General de Naciones Unidas (Resolución 50/6, de 9 de noviembre de 1995). La sentencia del TC cita también la Resolución de la misma Asamblea General, de 27 de marzo de 2014 («Integridad territorial de Ucrania»), referida a la invalidez del referéndum celebrado en la República Autónoma de Crimea y la Ciudad de Sebastopol el 16 de marzo de 2014. De todo ello, se deduce de forma coherente que puesto que el referéndum carece de validez jurídica interna, automáticamente carece de validez en el plano internacional. 
De hecho, desde la perspectiva del Derecho Internacional, el derecho de autodeterminación (art. 1.2 de la Carta de las Naciones Unidas) solo está permitido cuando concurran unos requisitos muy precisos y, en consecuencia, no se pueden aplicar al caso de Cataluña ni las citas que aparecen en el preámbulo de la Ley impugnada del art. 1 de los Pactos de Naciones Unidas de derechos civiles y políticos y de derechos económicos, sociales y culturales (1966), que recogen expresamente, el derecho de libre determinación de «todos los pueblos», ni de la Declaración sobre los Principios del derecho Internacional (Resolución 2625, de 24 de octubre de 1970), cuando ésta enuncia el principio de libre determinación de los pueblos.

Como ya se señaló anteriormente, es el proceso descolonizador el ámbito en el que ha de interpretarse el referido derecho de autodeterminación, lo que no cabe en el caso de Cataluña, por formar parte ésta de un Estado democrático, que tiene un gran nivel de descentralización y respeta el Estado de Derecho. Ello quiere decir que el proclamado derecho de separación solo tendría encaje «en supuestos de dominación colonial, pueblos anexionados por conquista, dominación extranjera u ocupación y pueblos oprimidos por violación masiva y flagrante de sus derechos» (STC 114/2017).

Por si esto fuera poco, la Ley objeto de recurso incumplía también los estándares fijados por la Comisión Europea para la democracia y el derecho, conocida como Comisión de Venecia. Como también indica la sentencia del TC, en las directrices de este órgano consultivo del Consejo de Europa sobre Democracia y Estado de derecho (Código de Buenas Prácticas sobre Referendos, de 16 de diciembre de 2006, complementado por la propia Comisión en su sesión del 16 y 17 de marzo de 2007) se establece que los efectos de los referendos jurídicamente vinculantes o consultivos deben estar claramente previstos en la Constitución o en la ley, no habiendo previsto como parece evidente que la Constitución española contemplara la posibilidad de celebración de un referéndum sobre la secesión de una parte del territorio nacional.

\section{6. ¿Hacia dónde vamos? Un ulterior examen de la STC 114/2017}

Lo primero que salta a la vista es que para los catalanes independentistas las opciones en juego han dejado de ser tres puesto que permanecer como una Comunidad más en el encaje constitucional actual parece desecharse de plano como opción de futuro. Por otra parte, las dos alternativas restantes podemos decir que se fusionan convirtiéndose en una debido a que la propuesta de que Cataluña mejore su condición mediante un "pacto blindado» con España a través de una reforma constitucional, solo sería plausible para los separatistas, en aras de lograr el verdadero fin, que no es otro que conseguir la independencia de Cataluña dentro de la Unión Europea.

El recurso ante el TC gozó por ello de una «extraordinaria relevancia constitucional», puesto que la Ley impugnada (como paso previo a la declaración de independencia de la Comunidad Autónoma de Cataluña) suponía una de las mayores afrentas a la Constitución española que por parte de un Parlamento autonómico puede concebirse en un Estado democrático y de derecho. Mediante esta Ley, el Parlamento de Cataluña, sobre la base de ejecutar una autoatribuida soberanía del pueblo catalán, se había colocado fuera del marco constitucional al convocar un referéndum que era inconstitucional tanto por razones sustantivas como competenciales. Como se recoge al comienzo de la sentencia:

La Ley parte de una pretendida soberanía del pueblo catalán (arts. 2 y 3.1) y atenta por ello contra el principio de soberanía nacional, la indisoluble unidad de la Nación 
española y el sistema democrático y el Estado de derecho consagrados en la Constitución, estando ordenados todos y cada uno de sus preceptos a la regulación, convocatoria y celebración de un referéndum secesionista (Antecedentes, STC 114/2017).

A pesar de ser la ley inconstitucional en su totalidad y nula la Ley de Cataluña 19/2017, de 6 de septiembre, denominada del referéndum de autodeterminación, resultando innecesario ahondar en los defectos de inconstitucionalidad de las disposiciones, teniendo en cuenta que la convocatoria de un referéndum sobre la independencia de una parte del Estado español implicaba por sí misma una vulneración constitucional de tal calibre que englobaba y absorbía cualquier otra vulneración de orden competencial, no se escatimó y se analizaron de forma individualizada cada uno de sus preceptos: violación frontal de los arts. 1.2 y $2 \mathrm{CE}$, en relación con el art. $168 \mathrm{CE}$, reiterándose la falta de competencia del legislador autonómico para convocar un referéndum.

Estaría de acuerdo en que la Ley objeto de recurso se hallaba viciada radicalmente de inconstitucionalidad al regular un referéndum para la eventual independencia de la Comunidad Autónoma de Cataluña (arts.1, 4 y conexos) sobre la base de una pretendida soberanía del pueblo catalán (art. 2) de la que sería representante el propio Parlamento de la Comunidad Autónoma (art. 3.1). En virtud de ello, la Ley se presentaba sin disimulos como norma suprema (art. 3.2), situándose así fuera completamente de la legalidad constitucional. Todo ello conculcaba de manera frontal lo dispuesto, entre otros preceptos, en los arts. 1.2, 2 y $168 \mathrm{CE}$; relativos, respectivamente, a la soberanía nacional residenciada en el pueblo español, a la indisoluble unidad de la Nación española, proclamada junto al reconocimiento y garantía del derecho a la autonomía de las nacionalidades y regiones que la integran, y al procedimiento agravado o reforzado de revisión de la Constitución que se establece en el último de los preceptos citados.

Pero no solo esto sobre lo que hemos insistido una y otra vez. También se habían infringido los arts. 1 y 222 del Estatuto de Autonomía de Cataluña. Tengamos en cuenta que en el primero se proclama que «Cataluña, como nacionalidad, ejerce su autogobierno constituida en Comunidad Autónoma de acuerdo con la Constitución y con el presente Estatuto, que es su norma institucional básica», en tanto que en el art. 222 se regula el procedimiento de reforma que afecta a los Títulos I y II del propio Estatuto.

Estima asimismo la demanda que, junto a esta «ruptura total y absoluta con el orden constitucional establecido», la Ley 19/2017 incurre en una inconstitucionalidad de carácter competencial, al desconocer las exclusivas competencias del Estado en orden a las consultas referendarias (art. 149.1.32 CE, en relación con los arts. 81.1 y $92 \mathrm{CE}$ ) y al pretender someter a una consulta de ese género cuestiones que afectan al fundamento mismo del orden constitucional; tales son las relativas a la identidad y unidad del sujeto soberano, que por ello no podrían ser encauzadas sino por el procedimiento de reforma previsto en el citado art. 168 CE. Los reproches de inconstitucionalidad de la demanda son también de orden procedimental, denunciando por ello el Abogado del Estado lo que denomina «simulacro» de procedimiento legislativo seguido en la tramitación de esta Ley.

Esta «vulneración flagrante y gravísima de nuestro sistema constitucional» resultaría también de la infracción por la Ley 19/2017 de los art. 1.3 y 168 CE, relativos, respectivamente, a la Monarquía parlamentaria como forma política del Estado español y al procedimiento para la revisión total de la propia Constitución o para la que pudiera afectar a partes determinadas de ella (Título Preliminar, Capítulo 
II, Sección $1^{\text {a }}$, del Título I o Título II); preceptos junto a los que se cita el art. $9.1 \mathrm{CE}$, de conformidad con el cual «los ciudadanos y los poderes públicos están sujetos a la Constitución y al resto del ordenamiento jurídico».

Del examen de la sentencia, me gustaría resaltar algunos aspectos importantes que allí se pusieron de manifiesto en relación con la extralimitación del parlamento autonómico:

A) La supremacía de la Constitución. Ningún poder constituido puede pretender situarse por encima de la norma fundamental y, sin embargo, ello es lo que precisamente hizo el Parlamento autonómico, al haber señalado que esta Ley predica de sí misma que «prevalece jerárquicamente sobre todas las normas que puedan entrar en conflicto» con ella (art. 3.2).

B) La primacía del Derecho de la Unión Europea sobre los ordenamientos jurídicos nacionales. El legislador autonómico también ignoró este principio queriéndose situar por encima de las disposiciones de la Unión Europea, del Derecho Internacional general y de los tratados internacionales. De hecho, conforme a la disposición final primera de la Ley, se afirma abiertamente que las normas nacionales se «continúan aplicando en todo aquello que no la contravenga» (sic.), en tanto que las europeas e internacionales se aplicarían "de acuerdo con esta Ley». Como vemos, claramente se está vulnerando uno de los principios estructurales del Derecho de la Unión Europea: el principio de primacía del Derecho de la Unión Europea.

C) La fuerza vinculante de la Constitución y la sujeción de los poderes constituidos, por supuesto, incluido el parlamento catalán. El legislador autonómico olvidó también «la permanente distinción entre la objetivación del poder constituyente [formalizado en la Constitución] y la actuación de los poderes constituidos, los cuales nunca podrán rebasar los límites y las competencias establecidos por aquél» [STC 76/1983, de 5 de agosto, FJ 4; en análogos términos, SSTC 15/2000, de 20 de enero, FJ 3, y 247/2007, de 12 de diciembre, FJ 8.a)].

D) Autonomía no es sinónimo de soberanía (STC 4/1981, de 2 de febrero, FJ 3 , y múltiples pronunciamientos ulteriores de análogo tenor). Ello quiere decir que el autogobierno de Cataluña, constituida en Comunidad Autónoma, no puede realizarse más que «de acuerdo con la Constitución y con el presente Estatuto, que es su norma institucional básica»; de tal manera que los poderes de la Generalitat, que «emanan del pueblo de Cataluña», han de ejercerse también consecuentemente, «de acuerdo con lo establecido en el presente Estatuto y la Constitución» (arts. 1 y 2.4 EAC).

E) Cataluña como España entera constituyen realidades socio-históricas anteriores a la Constitución de 1978, sin embargo, «desde el punto de vista jurídico-constitucional, el 'pueblo de Cataluña' [...] integra, sin embargo, un sujeto que se constituye en el mundo jurídico en virtud del reconocimiento constitucional (al igual que sucede con el conjunto del 'pueblo español' del que, conforme al art. 1.2 CE, emanan todos los poderes del Estado» (STC 42/2014, FJ 3).

Es por todo ello por lo que, a mi modo de ver, se puede considerar este fallo como un litigio estratégico con notable carácter pedagógico para los ciudadanos y absolutamente acertado en su argumentación, al declarar la inconstitucionalidad y 
nulidad, en su integridad, de la Ley del Parlamento de Cataluña 19/2017, de 6 de septiembre, llamada «del referéndum de autodeterminación» (art. 39.1 LOTC).

\section{El respeto de las minorías y la doctrina racialista en Cataluña}

Vilajosana creo que se equivoca cuando se refiere a los Tratados de la Unión Europea (en mayúscula) para reforzar su posición y relaciona la cuestión del derecho a decidir de los catalanes con el respeto de las minorías, citando el art. 2, que reza así: «La Unión se fundamenta en los valores del respeto a la dignidad humana, de la libertad, de la democracia [...] y del respeto a los derechos humanos, incluidos los derechos de las personas pertenecientes a minorías».

Como ha resaltado Tobeña, es cierto que el independentismo catalán tiene algo de excepcional puesto que, por una parte, es la primera vez en la Unión Europea en que una región aprovecha el contexto democrático, sin recurrir al levantamiento violento, para conquistar la segregación. Y, por otra parte, también es especial porque viene impulsado por la intelligentsia catalana, esto es, por las élites con mejor posición económico-social y más cosmopolitas:

No surge por agravios económicos, pobreza o explotación, sino al revés, son las élites, las clases medias y profesionales más destacadas las que deciden que el marco en el que viven es una rémora y se lo montarían mejor solos» (Tobeña, 2017, p. 6).

Parece evidente que, como con acierto ha destacado Savater en el artículo en prensa La agresión independentista (14 de noviembre de 2017), recogido en su libro Contra el separatismo (2017), por el que citaremos, no cabe justificar la independencia alegando que la población catalana fuera o sea víctima de una represión brutal, criminal y exterminadora, que no respeta los derechos humanos, como la que tuvo lugar por el ejército serbio de Milosevic en Kosovo o el ejército chino en el Tíbet. Por el contrario, en Cataluña se respetan los derechos humanos y los derechos fundamentales y por eso esta vía de justificación se convierte en una alternativa ilusoria, inviable y absurda para los separatistas. Con palabras del propio Savater: "Los separatistas catalanes, con astucia diabólica (si no suena demasiado melodramático), intentan hacerse pasar por kosovares o tibetanos europeos, pacientes de una represión sin mesura e indiscriminada» (Savater, 2017, p. 11). De ahí que, a su juicio, nos les falte razón a los que creen que nos encontramos instalados en la era de la postverdad.

Conviene dejar bien claro, siguiendo a Savater, que en lo que al proyecto separatista catalán se refiere, la legislación internacional no está de su lado, y así lo demuestra la declaración de la ONU sobre autodeterminación unilateral (1970), la cual sólo resulta comprensible en situaciones coloniales, como ya hemos dicho, pero nunca en casos en que el "pueblo» que quiere emanciparse forma parte de un espacio político «donde no se discrimina a nadie por su raza, credo o color». Más bien, podríamos afirmar que son los separatistas los que quieren discriminar al resto de la población por su raza, al exigir, por ejemplo, un adoctrinamiento educativo, el dominio de la lengua catalana para poder desarrollarse sin trabas en el territorio de Cataluña.

Estas reflexiones de Savater son especialmente importantes porque, desde mi punto de vista, frente a la visión habitual que atribuye al nacionalismo catalán una fundamentación meramente cultural o lingüística, debería tomarse en consideración la sugerente y provocadora tesis defendida por Francisco Caja en La raza catalana (2009), donde apoyándose en los propios textos fundacionales de los referentes e ideólogos del catalanismo trata de demostrar el carácter cientifista y racial de la 
doctrina catalanista. Conforme a esta teoría, el núcleo de la doctrina catalanista es la doctrina de la raza, hasta el punto de poder llegar a afirmar que el nacionalismo es algo así como «una especie de racialismo».

El autor se sirve para apoyar sus tesis de las doctrinas defendidas por numerosas e importantes figuras, que merecerían un estudio a fondo y en las que ahora me resulta imposible detenerme con la profundidad que ello requeriría pero, entre otros, destacan Valentín Almirall (1841-1904) y Pompeu Gener (1848-1920). Lo que parece demostrable, a juzgar por esta obra de Caja, es que poco a poco, fue cristalizando el catalanismo a partir de la doctrina racial importada de Francia gracias a la labor que allí desarrollaron Jules Soury y la Société d'Anthropologie de París de Paul Broca. La raza se convierte así en un principio sustancial (Caja, 2009, p. 89), que según resaltaban con gran orgullo debería conducir a la humanidad (Caja, 2009, p. 92). No es que se rechazase el igualitarismo en la convivencia social sino que lo que se rechaza abiertamente es la igualdad.

El grupo de Gener se agrupó en torno a la Revista Joventut, donde publicará el manifiesto fundacional, llamado Manifiesto de los supernacionales. Si este grupo acuñó la expresión Supernacional frente a la de Internacional, ello se debió a que Internacional se consideraba una derivación lógica del principio fraternal cristiano, del principio igualitario democrático. A partir del cierre de la Revista Joventut (1906) la influencia de Gener irá decreciendo aunque «el catalanismo ya podría reclamarse moderno gracias al racialismo, a la función 'idealizadora' de la raza» (Caja, 2009, p. 113).

Almirall y Gener llegaron a difundir la doctrina de las dos razas hasta países como México, como prueban los célebres Quaderns de l'exili (1943-1947), Revista mensual publicada en Coyoacán y dirigida por el grupo formado por Joan Sales, Raimon Galí, Lluís Ferrán de Pol y J.M. Ametlla, entre otros. Respaldando a este grupo de exiliados en México tras la guerra civil, se encontraba también el que fuera rector de la Universidad Autónoma de Barcelona (1933-1939), consejero de Justicia del Gobierno de la Generalidad (1937) y arqueólogo y prehistoriador de renombre internacional, el eminente Pere Bosch-Gimpera (1891-1974). El tono de los escritos de este grupo no puede ser más contundente: «Las ambiciones características de una raza en marcha son el poder y la expansión sobre la tierra, aunque sea en perjuicio de otras» (Caja, 2009, p.117); "Cataluña es esa base étnica inmutable, indestructible; es ella y no los individuos la que actúa. Es ella la que determina las formas, incluso y sobre todo las políticas, específicas de Cataluña. La que crea el derecho, la lengua, la cultura», (Caja, 2009, pp-125-126). De ahí que se haya llegado a afirmar que Bosch-Gimpera se convierte en cierto sentido en el discípulo espiritual de Pompeu Gener.

Otro de los personajes sobre el que merecería la pena ahondar es el político y Doctor Bartomeu Robert (1842-1902), quien desde planteamientos cientifistas, impulsó el organicismo, como rasgo ideológico que impulsaría el catalanismo hacia el racialismo. Es en este momento cuando emergen las siguientes ideas: la nación orgánica, Cataluña, tiene alma: el Volksgeist o Volksseele; no solo los individuos son únicos, también lo son las naciones; la raza manda frente a la voluntad política que nada puede hacer.

El racialismo catalán se va así transformando paulatinamente en esa forma ideológica que naturaliza la desigualdad jurídico-política de los seres humanos, a través de las ideas de profesionales, vinculados al mundo de la política, como el médico Hermenegild Puig i Sais (1860-1941), el psiquiatra Domènec Martí i Julià (1861-1917) o el escritor Enric Prat de la Riba (1870-1917) quien expone de forma 
clara sus ideas racialistas en la obra Nacionalitat Catalana (1906). Fichte se convertirá por ello en una pieza decisiva en esta defensa del catalanismo, erigiéndose como paradigma su trilogía raza-nación-lengua: «Todos los pueblos que hablan una misma lengua deben formar una misma nación, porque pertenecen a una misma raza» (Caja, 2009, p. 290).

Por último, en este recorrido un tanto apresurado de autores que defendieron la doctrina de la raza catalana, siguiendo la obra de Caja, deberían mencionarse también aunque sea someramente a dos más: el periodista y político Antoni Rovira i Virgili (1882-1949), por su intento persistente de conjugar el pensamiento de izquierdas y el nacionalismo, aunando el intento de apoyar el sentimiento separatista a partir del concepto de raza pero también a partir del concepto de alma; y el político Daniel Cardona i Civit (1890-1943), quien proclamaría abiertamente: «Y el nacionalismo, como expresión fiel de la raza, como obra inexorable de la naturaleza, llevará al triunfo definitivo. Es inútil oponerse a ello, porque ir contra el nacionalismo catalán, es ir contra natura. Porque la naturaleza no es sino expresión, 'plasmación de las centurias que han formado la tierra catalana'» (Caja, 2009, pp. 338-339).

Podríamos seguir cronológicamente refiriéndonos a muchos más autores, siguiendo la interesante investigación realizada por Caja, hasta llegar a nuestros días, que han ido sembrando la doctrina racialista en aras de separar a Cataluña del resto de España. Sin embargo, este breve y rápido esbozo de nuestra historia quizás nos ayude a entender mejor dónde nos encontramos en el momento actual y cómo no tiene sentido alguno apelar a las normas internacionales para justificar una opción que conculca derechos y, por encima de todo, el valor de la igualdad.

\section{El separatismo: una guerra de sentimientos y emociones}

Creo que nadie duda a estas alturas que el debate sobre el denominado «encaje de Cataluña» o independencia se ha convertido en un asunto perenne y parece tornarse imparable. Verdaderamente, estamos ante una encrucijada histórica. Los independentistas radicales se retrotraen al Memorial de Agravios que se presentó al rey Carlos III en 1760, al segundo Memorial de Agravios de los catalanes, sometido a la consideración de Alfonso XII en 1885, al Proyecto de Estatuto de Autonomía de 1919 - que no llegó nunca a ser votado por las Cortes-, al de 1932 que sí que se aprobó por la República, con graves recortes, como también lo fue el de 1979. Y, por supuesto, al de 2006, que aunque fue aprobado por el Parlamento Catalán y las Cortes españolas, fue tumbado por el Tribunal Constitucional, en el fallo de julio de 2010. Asimismo, la petición de consulta popular convocada en 2014 para el 9 de noviembre de aquel año fue rechazada abiertamente por el Gobierno español por su inconstitucionalidad (Giner, 2015, p. 242).

Ahora bien, cuando uno reflexiona sobre los últimos acontecimientos vividos en Cataluña, llega a la conclusión de que lo que estamos viviendo es una verdadera guerra de sentimientos y emociones. No lo pudo decir más claro Mario Vargas Llosa en la marcha de Barcelona por la unidad de España, que convocó la Societat Civil Catalana a primeros de octubre de 2017: «Uno puede abominar del nacionalismo que ha ensangrentado Europa, (...) y sin embargo exhibir una bandera rojigualda con toda naturalidad» (Savater, 2017b, p. 9). También en esta misma línea Savater efectuó declaraciones contundentes tanto en su artículo en prensa, titulado La agresión independentista (2017a), como en su libro Contra el separatismo (2017b), ambos anteriormente citados:

Tenemos que dejar claro que lo que pretende imponerse en Cataluña no es simple nacionalismo, es decir, exaltación y apego a lo propio, aunque sea con desmesura; es 
separatismo, es decir, aborrecimiento de lo español, odio feroz al no nacionalista y, sobre todo, exclusión práctica de quienes no comulgan con el dogma del sacrosanto pueblo catalán y subversión de cuanto representa al Estado español (Savater, 2017, p. 9).

Es por ello que me parece crucial en estos tiempos no confundir el nacionalismo con el separatismo porque éste, a fin de cuentas, es

una agresión deliberada, calculada y coordinada contra las instituciones democráticamente vigentes y contra los ciudadanos que las sienten como suyas sin dejar por ello de considerarse catalanes. No es un delirio más o menos grave sino un ataque en toda regla al núcleo más importante de nuestra garantía de ciudadanía, el Estado de derecho (Savater, 2017, p. 9).

El separatismo, a diferencia de lo que ocurre con los movimientos políticos, parece gozar de un "carácter maligno», desde un punto de vista mítico-religioso. Con palabras, sin tapujos, de Savater:

El diablo es, etimológicamente, el separador, diabolum, el que desune y rompe los lazos establecidos. La tarea diabólica es la fechoría antihumanista por excelencia, separar a los que conviven juntos y obligarlos a detestarse unos a otros, a alejarse: sembrar la discordia, el desgarro de los corazones. Es de lo más desdichado que tantos separatismos pequeños y grandes encuentren terreno abonado en España, hasta el punto de que cualquier símbolo regional -y si es posible excluyente- sea visto como algo liberador, progresista, por la izquierda lerda y sus asimilados: es prueba de que tenemos un país de todos los diablos... (Ibid., pp. 9-10).

Creo que cuando uno se plantea cuál o dónde está la raíz de este separatismo diabólico, debería tener en cuenta no un único factor sino varios simultáneamente porque, como con acierto se ha puesto de relieve,

la Cataluña de hoy es el resultado de varias corrientes históricas que, juntas, determinan su singularidad. Son, entre otras, los siguientes: un pasado remoto fuertemente feudal; una revolución burguesa autóctona, tanto la mercantil como la industrial; una casi permanente pertenencia del país, a lo largo de los tiempos, a unidades políticas más amplias; una tradición, interrumpida desde fuera, de autogobierno; una gran ciudad, Barcelona, como capital propia; un alto grado de conciencia étnica y nacional de los catalanes; una lengua propia; una sociedad civil muy sustancial; y, finalmente, una cultura muy característica (Giner, 2015, p. 15).

Dicho esto, y teniendo presente que cualquier análisis de la sociedad catalana exigiría no ignorar la interacción mutua de todos estos elementos, creo que un factor decisivo ha sido y es la conciencia racial catalana, alimentada por una doctrina racialista perfectamente trabada durante siglos, que sirve de motor para la pasión y devoción secesionista porque no debe olvidarse que el movimiento independentista, gracias a la inteligencia del activismo que lo apoya, ha logrado «enamorar, seducir, persuadir a la mitad de los catalanes con un horizonte espléndido y para ello ha encendido todos los motores de la pasión victoriosa» (Tobeña, 2017, p. 6). Es por ello que conforme señala el Catedrático de Psiquiatría de la Universidad Autónoma de Barcelona, autor de La pasión secesionista: psicobiología del independentismo (2017b), más que ante

un desvarío, una sinrazón, un delirio, una locura, una obnubilación o una especie de hipnosis, es una pasión de un grupo que quiere conseguir la victoria y alcanzar el objetivo que se ha propuesto y para eso necesita motores pasionales a nivel colectivo (Tobeña, 4 de noviembre de 2017, p. 6). 
Esta tesis encajaría a la perfección con la visión que aquí mantengo de que estamos inmersos en una guerra de sentimientos y emociones que con las reglas que imperan en el Estado de Derecho es necesario pacificar y al mismo tiempo racionalizar. Como recordaba Vargas Llosa en su discurso por la unidad de España «la pasión puede ser también destructiva y feroz cuando la mueven el fanatismo y el racismo». En todo caso -y termino- lo acontecido el 1 de octubre de 2017 en España es uno de los mayores golpes que han recibido las instituciones españolas en los últimos tiempos al pretenderse poner las instituciones al servicio del independentismo. Digamos por ello «no» al autoritarismo, tratando de recuperar el modelo ilustrado de Kant y el concepto de voluntad general de Rousseau para aproximarnos entre todos de una manera serena y racional a la verdad.

Bibliografía

Alexy, R. (1993). Teoría de los derechos fundamentales. Madrid, España: Centro de Estudios Constitucionales.

Aparicio Aldana R. K. (2013). La interpretación jurídica del derecho a la intimidad. En A. Ollero (Ed.), IX Jornadas Internacionales de Derecho Natural. Buenos Aires, Argentina: Facultad de Derecho - UCA.

Bulygin, E. (1987). Sobre el status ontológico de los derechos humanos. Doxa. Cuadernos de Filosofía del Derecho, 4, pp. 79-84.

Bobbio, N. (1965). Giusnaturalismo e positivismo giuridico. Milano, Italia: Edizioni di Comunità.

Caja, F. (2009). La raza catalana: El núcleo doctrinal del catalanismo. Madrid, España: Ediciones Encuentro, S.A.

Capella Hernández, J. R. (1992). Lo 'jurídicamente verdadero' es lo que la autoridad decide. En J. R. Capella Hernández. Cuadernos Azul y Marrón. Tres lecciones de introducción al derecho. Barcelona, Esplugues de Llobregat, España: Editorial Graf-Signo.

Díaz. E. (1998). Estado de Derecho y sociedad democrática. Madrid, España: Taurus.

Díaz, E. (1996). De las funciones del Derecho: organización y cambio social. En J. L. Iglesias Prada (coord.), Estudios Jurídicos en Homenaje al Profesor Aurelio Menéndez (pp. 5444-5464). Madrid, España: Civitas.

Díaz, E. (1984). De la maldad estatal y la soberanía popular. Madrid, España: Debate.

Díaz, E. (1978). Legalidad-legitimidad en el socialismo democrático. Madrid, España: Civitas.

Díaz, E. (1966). Estado de Derecho y sociedad democrática. Madrid, España: Cuadernos para el Diálogo.

Dworkin, R. (2008). La democracia posible. Principios para un nuevo debate político. Barcelona, España: Paidós.

Dworkin, R. (2006). Is democracy possible here? New Jersey, Estados Unidos: Princeton University Press.

Dworkin, R. (1984). Los derechos en serio. Barcelona, España: Ariel.

Dworkin, R. (1977). Taking Rights seriously. Londres, Reino Unido: Gerald Duckworth \& Co. Ltd.

Ezquiaga Ganuzas, F. J. (2010). Conflictos normativos e interpretación jurídica. Michoacán, México: Tribunal Electoral del Estado de Michoacán.

Ferrajoli, L. (2001). Derechos y garantías. La ley del más débil. Madrid, España: Trotta.

Giner, S. (2015). Cataluña para Españoles. Madrid, España: Catarata.

Granado Hijelmo, I. (1997). Reflexiones jurídicas para un tiempo de crisis. Nuevo orden internacional, constitución europea y proceso autonómico español. Barcelona, España: Ediciones Internacionales Universitarias. 
Hart, H.L.A. (2007). Derecho, libertad y moralidad. Las conferencias Harry Camp en la Universidad de Stanford (1962). Madrid, España: Dykinson.

Hermida del Llano, C. (2017). La Mutilación Genital Femenina. El declive de los mitos de legitimación. Valencia, España: Tirant lo Blanch.

Hermida del Llano, C. (2015). El matrimonio: ¿Una antropología desnaturalizada?. En C. Hermida del Llano y J. A. Santos (Eds.), Una Filosofía del Derecho en acción. Homenaje al Profesor Andrés Ollero (pp. 2157-2172). Madrid, España: Congreso de los Diputados - Universidad Rey Juan Carlos.

Hermida del Llano, C. (2012). Diálogo tras el debate. Andrés Ollero con Cristina Hermida del Llano. En A. Ollero y J. A. García Amado y C. Hermida del Llano (eds.), Derecho y moral: una relación desnaturalizada (pp. 265-325). Madrid, España: Fundación Coloquio Jurídico Europeo.

Hermida del Llano, C. (2005). Los derechos fundamentales en la Unión Europea. Barcelona, España: Anthropos.

Laporta, F.J. (1995 [1993]). Entre el Derecho y la Moral. México D.F., México: Fontamara.

Maccormick, N. (2010). H.L.A. Hart. Madrid-Barcelona, España, y Buenos Aires, Argentina: Marcial Pons.

Ollero, A, García Amado, J.A y Hermida del Llano, C. (2012). Derecho y moral. Una relación desnaturalizada. Madrid, España: Fundación Coloquio Jurídico Europeo.

Ollero, A. (2014). En diálogo con Dworkin: Moralidad política y Derecho Natural. Anales de la Real Academia de Ciencias Morales y Políticas, 91, pp. 461-478.

Ollero, A. (2013a). El matrimonio natural (Casatoria naturala). Revista Romana de Drept Privat. Romanian Review of Private Law, 3, pp. 357-371.

Ollero, A. (16 agosto, 2013b). El eclipse del derecho. ABC, p. 3.

Peces-Barba, G. (1991). Curso de Derechos Fundamentales (I) Teoría General. Madrid, España: Eudema Universidad.

Peces-Barba, G. (1973). Derechos Fundamentales. I. Teoría general. Madrid, España: Guadiana.

Pérez Luño, A. E. (1984). Derechos Humanos, Estado de Derecho y Constitución. Madrid, España: Tecnos.

Robles Morchón, G. (1992). Los derechos fundamentales y la ética en la sociedad actual. Madrid, España: Cuadernos Civitas.

Robles Morchón, G. (1988). Los Derechos Fundamentales en la Comunidad Europea. Madrid, España: Ceura.

Savater, F. (14 noviembre, 2017a). La agresión independentista. El País. Recuperado de

https://elpais.com/cultura/2017/11/13/actualidad/1510576109 231556.htm/

Savater, F. (2017b). Contra el separatismo. Barcelona, España: Ariel, Planeta. Versión en libro electrónico epub, noviembre de 2017.

Tinnefeld, M., Schmale, W. (2010). Identität durch Grundrechte. DuD, 34, pp. 523528.

Tobeña, A. (4 noviembre, 2017). La pasión y la devoción secesionistas para lograr el paraíso es de raíz religiosa. La voz de Galicia, p. 6. Recuperado de https://www.lavozdegalicia.es/noticia/espana/2017/11/04/pasion-devocionsecesionistas-lograr-paraiso-raiz-religiosa/0003 201711G4P6991.htm

Tobeña, A. (2017b). La pasión secesionista: psicología del independentismo. Barcelona: ED Libros.

Vidal Gil, E.J. (1999). Los conflictos de derechos en la legislación y jurisprudencia españolas. Un análisis de algunos casos difíciles. Valencia, España: Universitat de Valéncia-Tirant lo Blanch. 
Vilajosana, J.M. (2020). Democracia y derecho a decidir. Eunomía. Revista en Cultura de la Legalidad, 18, pp. 375-391.

Von Wright, G.H. (1971). Norma y acción. Una investigación lógica. Madrid, España: Tecnos.

Weber, M. (1993 [1922]). Economía y Sociedad. Esbozo de sociedad comprensiva. Ciudad de México, México: Fondo de Cultura Económica. 